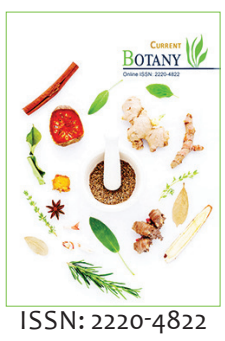

Received: October 08, 2020 Revised: December 19, 2020 Accepted: December 25, 2020 Published: February 19, 2021

*Corresponding Author: S. Patil Manasi , Email:manasipatil202@ gmail.com

\section{Influence of plant growth regulators on fatty acid composition of Simarouba glauca DC.}

\author{
S. Patil Manasi'*, V. Waghmode Ahilya', Chirag Narayankar², \\ D. K. Gaikwad ${ }^{3}$
}

'Department of Botany, Sadguru Gadage Maharaj College, Karad, Maharashtra - 415124, India, ${ }^{2}$ Department of Botany, Shivaji University, Kolhapur, Maharashtra-416004, India, ${ }^{3}$ Dr. B.A.M.U., Sub-Campus, Osmanabad, Maharashtra-413501, India

\begin{abstract}
Simarouba glauca is a medicinally important oil yielding plant. It is a rainfed wasteland evergreen edible oil tree. Presowing soaked seeds of Simarouba glauca in various Plant Growth Regulators (PGRs) are analyzed to estimate their fatty acid composition. The fatty acids extraction was done using petroleum ether and fatty acid methyl esters (FAMEs) were analyzed by Gas Chromatography with Flame Ionization Detector (GC-FID). Due to the application of growth regulators stearic acid, lingoceric acid and linolenic acid enhances noticeably, while, total saturated fatty acids are augmented due to cysteine, Salicylic Acid (SA) and methionine treatments and monosaturated fatty acids elevated due to the application of 6-Benzylaminopurine (6-BA) whereas polyunsaturated fatty acids enhanced in response to Gibberellic Acid(GA) and Chlormequat chloride (CCC). The PGR induced changes in fatty acid composition predominantly in polyunsaturated fatty acids may certainly recover the oil quality of S. glauca seeds.
\end{abstract}

KEYWORDS: 6-BA, GA, SA, CCC, Cysteine and Methionine

\section{INTRODUCTION}

Simarouba glauca belongs to family Simaroubaceae. It is commonly known as Laxmitaru. It is rainfed wilderness, evergreen, oil tree. It is commonly nominated as 'dysentery bark' as bark is significant constituent of herbal medicine used in dysentery. The bark and leaf extract is prominent for their different types of medicinal properties used as haemostatic, antipyretic, antiparasitic, antidysentric, vermifuge and anticancerous. The bark is used to treat fever, malaria, abdomen and bowel disorders, haemorrhages, ameobiasis. The fruit pulp and seeds are also having curative property such as pain-relieving, antimicrobial, antiviral, stomachic tonic (Joshi \& Joshi, 2002). Glaucarubinone isolated from the Simarouba plant, showed anticancer property (Encyclopedia of world medicinal plants). Numerous quassinoid from S. glauca seed have exhibited cytotoxic activity in vitro against KB cells (human oral epidermoid carcinoma), including glaucarubin, glaucarubinone, glaucarubol and glaucarubolone (Polonsky et al., 1975; Valeriote et al., 1998). Fatty acids usually found to be observed in the type of esters of glycerols i.e. triacyl glycerols in natural fats of animal and plant source. Myristic acid (Cl4:0), Palmitic acid (Cl6:0), stearic acid (C18:0), oleic acid (C18:1) and linoleic acid are the most frequent fatty acids (Christie, 2003) All the plant cells consist of fatty acids, where they function as membrane integrant, storage products, metabolites and a energy source (Wada et al., 1994). The fatty acids are also vital nutrient substances and metabolites in plants as well as animals (Chen \& Chuang, 2002). The present study was aimed to study the effect of PGRs on the fatty acid composition of $S$. glauca seeds to assess any changes in the fatty acid composition with regards to germination studies or for oil extraction in future.

\section{MATERIAL AND METHODS}

Seeds of Simarouba glauca were pre-soaked in PGRs (6-BA, GA, SA, CCC, Cysteine and Methionine) $100 \mathrm{ppm}$ concentration for $24 \mathrm{hrs}$ and Kept for germination. After germination germinated seeds of $S$. glauca were dehydrated. The seed material was crushed and the lipids from the crushed seed were taken out in petroleum ether by means of soxhlet apparatus. To analyze FAS from the oil fractions by gas chromatography technique, the oil was subjected to transesterification to obtain the fatty acid methyl ester. The fatty acid methyl ester fractions were

Copyright: (C) The authors. This article is open access and licensed under the terms of the Creative Commons Attribution License (http://creativecommons.org/licenses/by/4.0/) which permits unrestricted, use, distribution and reproduction in any medium, or format for any purpose, even commercially provided the work is properly cited. Attribution — You must give appropriate credit, provide a link to the license, and indicate if changes were made. 
eluted with petroleum ether: diethyl ether $=50: 50(\mathrm{~V} / \mathrm{V})$. The fractions were redissolved in hexane and used for GC analysis.

Fatty acid methyl esters (FAMEs) were analyzed by GC-FID (A SHIMADZU GC-17-A gas chromatograph with flame ionization detector). The recognition of fatty acids was approved by comparing with the methyl esters of standard fatty acids.

\section{RESULTS}

It is revealed from the Table 1 and Figure 1 that the saturated, monounsaturated and polyunsaturated fatty acids are $44.50 \%$, $51.70 \%$ and $3.70 \%$ respectively. The key fatty acids of S.glauca seed oil are methyl esters of palmitic acids, stearic acid, arachidic acid, oleic acid, lenoleic acid and linolenic acid. By application of growth regulators stearic acid, lingoceric acid and linolenic acid enhanced greatly, while, total saturated fatty acids are increased by application of cysteine, SA and methionine applications and monosaturated fatty acids elevated only in 6-BA and poly unsaturated fatty acids increases due to treatment of GA and CCC. Whereas methyl esters of elaidic acid and total of trans fat are not diagnosed from seeds of $S$. glauca. Evidence suggests that fatty acid content in oil seeds may be governed by levels of endogenous plant growth substances, which in turn may be altered by appliance of exogenous, synthetic PGRs.

\section{DISCUSSION AND CONCLUSION}

It is well known that generally plant hormones may change fatty acid composition of treated plants. In soybean zygotic embryo cotyledons are observed auxin-regulated change of fatty acid content (Liu et al., 1995). Gibberellins influence the content of lipid of endoplasmic reticulum in aleurone layers of barley (Grindstaff et al., 1996). Study of Hedin et al. (1988) revealed that in maize whole fatty acid content was decreased in response to GA. In the present study it is noticed the better level of stearic, lingoceric acid as saturated fatty acids and linoleic acid and linolenic acid as polysaturated fatty acids in reaction to GA presowing soaking applications as shown by Mostafa et al. (2005) and Bano et al. (2009). It is also noticed that myristoleic acid found to be detected in response to GA treatment only and not detected in control as well as other treatments.

Ivanova et al. (2008) studied cadmium induced changes in maize leaves and the protective role of salicylic acid. They observed pretreatment of maize plant with SA seemes to have an insignificant effect on fatty acid content. There was a slight increase of linolenic acid and decrease of all saturated fatty acid. They further concluded that SA plays a protective role on the lipid membranes of Cd-treated maize plants. $\alpha$-linolenic acid was stimulated in 6-BA treated plants as compared to control in Lemna minor (Hurtubise et al.,1992). Cytokinin treatment changes the lipid fatty acids of green leaves Coleus blumei Benth. and Impatiens sultani Hook (Kull et al., 1978). In both species the proportion of linolenic acid increases and that of palmitic acid decreases. oil content in the seeds of sunflower (Helianthus annuus L.) was increased due to CCC treatment either at pre

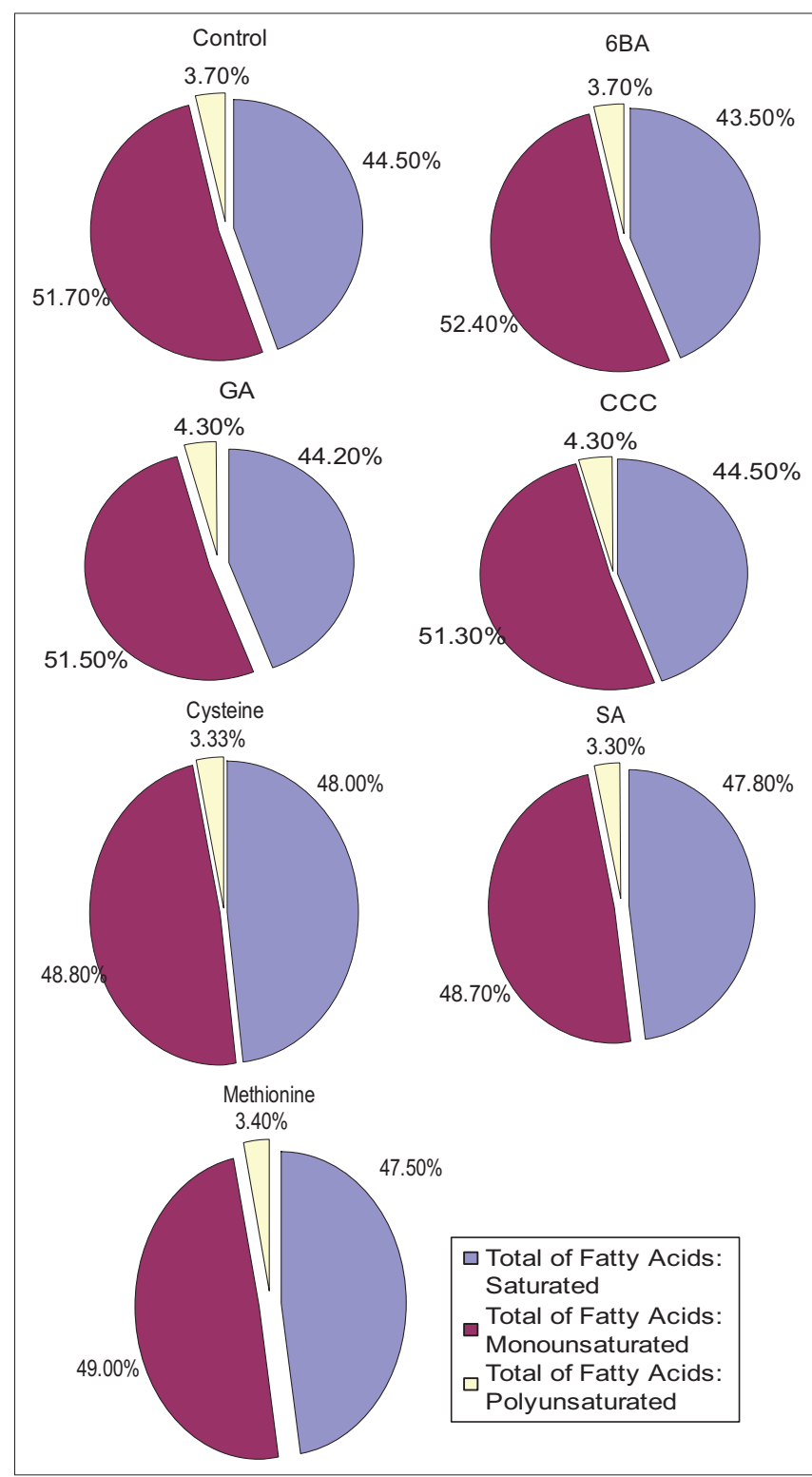

Figure 1: Relative proportion of saturated, monosaturated and polysaturated fatty acids of $S$. glauca seed oil

or post flowering stage (Pando \& Srivastava, 1987). Outcome of PGRs on productivity of corn (Zea mays L.) was studied by Hedin et al. (Hedin et al., 1988. They observed CCC enhanced the fatty acid substances. In the present study, it is also evident that the Behenic acid methyl ester (C22:0), Myristoleic acid methyl ester (C14:1), Cis-11 Eicosenoic acid methyl ester (C20:1), Cis-10-Heptadecanoic acid methyl ester (C17:1) and omega 3 fatty acid Cis-1 1,14,17- Eicosatrienoic acid methyl ester $(\mathrm{C} 20: 3 \mathrm{n} 3)$ are found to be induced in response to presowing soaking of these PGRs which are not detected in control seeds. With these alterations in fatty acids during germination of $S$. glauca seeds it reveals that there is a significant change in the fatty acid content in response to plant growth regulators. The present study reveals that the PGR induced changes in fatty acid composition especially in polyunsaturated fatty acids may certainly improve the oil quality of $S$. glauca seeds and these 
Table 1: Effect of plant growth regulators on fatty acid composition of S. glauca seed oil

\begin{tabular}{|c|c|c|c|c|c|c|c|c|}
\hline \multirow[t]{2}{*}{ No. } & \multirow[t]{2}{*}{ Name of the Fatty Acids } & \multicolumn{7}{|c|}{ Plant growth regulators } \\
\hline & & control & 6BA & GA & $\mathrm{CCC}$ & Cysteine & SA & Methionine \\
\hline 1. & Myristic acid methyl ester (C14:0) & $0.20 \%$ & $0.10 \%$ & $0.10 \%$ & $0.20 \%$ & $0.10 \%$ & $0.10 \%$ & $0.20 \%$ \\
\hline 2. & Palmitic acid methyl ester (C16:0) & $14.70 \%$ & $14.40 \%$ & $14.70 \%$ & $15.10 \%$ & $9.80 \%$ & $10.80 \%$ & $12,19 \%$ \\
\hline 3. & Heptadecanoic acid methyl ester (C17:0) & $0.10 \%$ & ND & $0.10 \%$ & ND & $0.10 \%$ & $0.10 \%$ & $0.10 \%$ \\
\hline 4. & Stearic acid methyl ester (C18:0) & $28.40 \%$ & $28.90 \%$ & $29.10 \%$ & $29 . .20 \%$ & $34.80 \%$ & $34.0 \%$ & $32.00 \%$ \\
\hline 5. & Arachidic acid methyl ester (C20:0) & $1.00 \%$ & ND & ND & ND & $2.50 \%$ & $2.20 \%$ & $1.60 \%$ \\
\hline 6. & Behenic acid methyl ester (C22:0) & ND & ND & ND & ND & $0.30 \%$ & $0.20 \%$ & $0.30 \%$ \\
\hline 7. & Lingoceric acid methyl ester (C24:0) & $0.10 \%$ & $0.10 \%$ & $0.20 \%$ & ND & $0.40 \%$ & $0.30 \%$ & $0.40 \%$ \\
\hline \multicolumn{2}{|c|}{ Total of Fatty Acids (Saturated) } & $44.50 \%$ & $43.50 \%$ & $44.20 \%$ & $44.50 \%$ & $48.00 \%$ & $47.80 \%$ & $47.50 \%$ \\
\hline 8 & Myristoleic acid methyl ester (C14:1) & ND & ND & $0.10 \%$ & ND & ND & ND & ND \\
\hline 9 & Palmitoleic acid methyl ester (C16:1) & $0.10 \%$ & ND & $0.10 \%$ & ND & ND & $0.10 \%$ & ND \\
\hline 10 & Oleic acid methyl ester (C18:In9c) & $51.60 \%$ & $52.40 \%$ & $51.30 \%$ & $51.20 \%$ & $48.70 \%$ & $48.60 \%$ & $49.00 \%$ \\
\hline 11 & Cis-11 Eicosenoic acid methyl ester (C20:1) & ND & ND & ND & ND & $0.10 \%$ & ND & ND \\
\hline 12 & Cis-10-Heptadecanoic acid methyl ester (C17:1) & ND & ND & ND & $0.10 \%$ & ND & ND & ND \\
\hline \multicolumn{2}{|r|}{ Total of Fatty Acids (Monounsaturated) } & $51.70 \%$ & $52.40 \%$ & $51,50 \%$ & $51.30 \%$ & $48 . .80 \%$ & $48.70 \%$ & $49.00 \%$ \\
\hline 13 & Linoleic acid methyl ester (C18:2n6c) & $3.40 \%$ & $3.60 \%$ & $3.90 \%$ & $4.00 \%$ & $3.10 \%$ & $3.30 \%$ & $3.00 \%$ \\
\hline 14 & Linolneic acid methyl ester (C18:2n6c) & $0.20 \%$ & $0.40 \%$ & $0.30 \%$ & $0.20 \%$ & $0.20 \%$ & $0.20 \%$ & $0.30 \%$ \\
\hline 15 & Cis-11,14,17- Eicosatrienoic acid methyl ester (C20:3n3) & ND & ND & ND & ND & ND & ND & $0.10 \%$ \\
\hline 16 & Cis- $5,8,11,14,17$ - Eicosapentaenoic acid methyl ester (C20:6n3) & $0.10 \%$ & $0.10 \%$ & $0.10 \%$ & ND & ND & ND & ND \\
\hline \multicolumn{2}{|r|}{ Total of Fatty Acids (Polyunsaturated) } & $3.70 \%$ & $3.70 \%$ & $4.30 \%$ & $4.30 \%$ & $3.33 \%$ & $3.30 \%$ & $3.40 \%$ \\
\hline 1 & Elaidic acid methyl ester (C18:1n) & ND & ND & ND & ND & ND & ND & ND \\
\hline 2 & Total of Trans Fat & ND & ND & ND & ND & ND & ND & ND \\
\hline
\end{tabular}

polyunsaturated fatty acids might be playing role in stimulation of seed germination of $S$. glauca.

\section{ACKNOWLEDGEMENTS}

The author is thankful to RUSA for Financial support to carry out this research work and Dr. M. M. Rajmane, Principal, Sadguru Gadage Maharaj College Karad for providing laboratory facilities.

\section{REFERENCES}

Bano, A., Khan, N., \& Faizanullah. (2009). Nutritive values of Brassica campestris $\mathrm{L}$. oil as affected by growth regulator treatments. JournalChemical Society of Pakistan 31(5), 819-822.

Chen, S. H., \& Chuang, Y. J. (2002). Analysis of fatty acids by column liquid chromatography. Analytica Chimica Acta, 465(1-2),145-155. https:// doi.org/10.1016/S0003-2670(02)00095-8

Christie, W. W. (2003). Lipid analysis: Isolation, separation, identification and structural analysis of lipids (pp.1-416). (Publ.) Bridgewater: The Oily Press.

Grindstaff, K. K., Fielding, L. A., \& Brodl, M.R. (1996). Effect of gibberellins and heat shock on the lipid composition of endoplasmic reticulum in barley aleurone layers. Plant Physiology, 110, 571-581. https://doi. org/10.1104/pp.110.2.571

Hedin, P.A., Williams, P., Davis, F. M., \& Thompson A. C. (1988). Effects of plant bioregulators on nutrients, insect resistance, and yield of corn (Zea Mays L.). Journal of Agricultural and Food Chemistry, 36(4), 746-748. https://doi.org/10.1021/jf00082a017

Hedin, P.A., Williams, W. P., Davis, F. M., \& Thompson A. P. (1988). Effects of plant bioregulators on nutrients, insect resistance, and yield of corn (Zea Mays L.). Journal of Agricultural and Food Chemistry, 36, 746-748. https://doi.org/10.1021/jf00082a017

Hurtubise, Y., Proteau, V., \& Grenier, G. (1992). Effects of benzyladenine on $\left[\mathrm{U}-{ }^{14} \mathrm{C}\right]$ acetate incorporation into lipids of Lemna minor. Phytochemistry, 31(11), 3827-3833. https://doi.org/10.1016/S00319422(00)97536-8

Ivanova, A., Krantev, A., Stoynova, Zh., \& Popova, L. (2008). Cadmiuminduced changes in maize leaves and the protective role of salicylic acid. General and Applied Plant Physiology, 34(3-4), 149-158.

Joshi, S., \& Joshi, S. (2002). Oil Tree-Laxmitaru glauca. (pp. 86). Bangalore, India: University of Agricultural Sciences and New Delhi, India: Indian council of Agricultural Research.

Kull, U., Kuhn, B., Schweizer, J., \& Weiser, H. (1978). Short-term effects of cytokinins on the lipid fatty acids of green leaves. Plant and Cell Physiology, 19(5), 801-810, https://doi.org/10.1093/oxfordjournals. pcp.a075654

Liu, W., Hildebrand, D.F., \& Collins, G. B. (1995). Auxin-regulated changes of fatty acid content and composition in soybean zygotic embryo cotyledons. Plant Science, 106(1), 31-42. https://doi. org/10.1016/0168-9452(95)04067-5

Mostafa, H. A. M., El-Bassiouny, H. M. S., Khattab, H. K. I. \& Sadak, M. S. (2005). Improving the characteristics of roselle seeds as a new source of protein and lipid by gibberellin and benzyladenine application. Journal of Applied Sciences Research, 1(2), 161-167.

Pando, S. B., \& Srivastava, G. C. (1987). Influence of cycocel on seed of sunflower (Helianthus annus L.). Indian J of Plant Physiology, 30(3), 305-307.

Polonsky, J., Baskévitch, Z., Gottlieb, H. E., Hagaman, E. W., \& Wenkert, E. (1975). Carbon-13 nuclear magnetic resonance spectroscopy of naturally occurring substances. XXXI. Carbon-13 nuclear magnetic resonance spectral analysis of quassinoid bitter principles. Journal of Organic Chemistry, 40(17), 2499-2504. https://doi.org/10.1021/ jo00905a017

Valeriote, F. A., Corbett, T. H., Grieco, P. A., Moher, E. D., Collins, J. L., \& Fleck, T. J. (1998). Anticancer activity of glaucarubinone analogues. Oncology Research, 10(4), 201-208.

Wada, H., Gombos, Z., \& Murata, N. (1994). Contribution of membrane lipids to the ability of the photosynthetic machinery to tolerate temperature stress. Proceedings of the National Academy of Sciences of the United States of America, 91(10), 4273-4277. https://doi.org/10.1073/ pnas.91.10.4273 